História (São Paulo)

Hospedarias de Imigrantes nas Américas: a criação da hospedaria da Ilha das Flores

Hostels of Immigrants in the Americas: the creation of the Hostel of Flowers'́ Island

Luís REZNIK

Universidade do Estado do Rio de Janeiro, São Gonçalo, RJ, Brasil.

Contato: lreznik@uol.com.br

Rui Aniceto Nascimento FERNANDES

Universidade do Estado do Rio de Janeiro, RJ, Brasil.

Contato: ruianiceto@hotmail.com

Resumo: A recepção aos imigrantes, em fins do século XIX, foi uma experiência comum aos países americanos. Foram criados dispositivos similares para dar conta do massivo deslocamento populacional do Velho Continente. Conhecer as hospedarias de imigrantes em sua universalidade e especificidades é uma forma de compreender como cada uma das sociedades estabeleceu suas relações com estrangeiros. Este texto tem como objetivo analisar a criação da Hospedaria de Imigrantes da Ilha das Flores, que funcionou entre 1883 e 1966, situada no Rio de Janeiro. Busca-se compreender como as demandas e experiências em curso moldaram a instituição.

Palavras-chave: imigração; hospedaria de imigrantes; Rio de Janeiro.

Abstract: The experience of receiving immigrants, in the late nineteenth century, was an experience shared by American countries. Similar apparatus have been created to deal with the massive displacement of the Old Continent. Knowing the hostels of immigrants in its universality and its specificities is a way to understand how each of the societies established their relations with foreigners. This paper aims to analyze the creation of the hostel for immigrants of Flowers' Island, which ran between 1883 and 1966, located in Rio de Janeiro. We seek to understand how the demands and ongoing experiences shaped the institution.

Keywords: immigration; hostel for immigrants; Rio de Janeiro.

Construção de um edifício adequado à recepção de imigrantes, em condições de comportar o movimento anual de 50.000 indivíduos; e organização de um serviço de informações, locação e venda de terras que habilite o colono recém-chegado a colocarse convenientemente segundo a sua aptidão, e no menor prazo;

Hospedagem até 8 dias;

Transporte gratuito da Corte para as províncias e daí para as localidades onde os imigrantes houverem de ser colocados. (SARAIVA, 1882, p. 208) 


\section{Hospedarias de Imigrantes nas Américas: a criação da hospedaria da Ilha das Flores}

Os deslocamentos populacionais entre o Velho e o Novo continentes, ocorridos desde o século XIX, constituem fenômenos de grande interesse entre pesquisadores das mais diferentes áreas de estudos. A bem da verdade, compreender as razões que levaram milhões de pessoas a se desenraizar e deixar as terras ancestrais, reconstruindo vidas e identidades, configurou-se como um instigante objeto de análise que envolveu homens de letras, de ciência e agentes públicos, desde aquele período. Conforme a vasta bibliografia já produzida, os movimentos migratórios são tema complexo e multifacetado e, por isso mesmo, propiciam uma variedade de perspectivas e abordagens.

Nosso interesse específico volta-se para os dispositivos criados com vistas à recepção, ao acolhimento e à triagem da leva populacional massiva que se deslocou em fins do século XIX para os países americanos. Particularmente, pretende-se problematizar a Hospedaria de Imigrantes da Ilha das Flores, órgão criado pelo governo imperial brasileiro em 1883. Apesar da sua existência ser sobejamente conhecida pela produção acadêmica sobre imigração, a Hospedaria da Ilha das Flores foi pouco estudada. ${ }^{1}$

Se é certo que a hospedaria foi fruto das preocupações suscitadas pelas políticas dirigidas aos imigrantes da passagem do século XIX para o século XX, o que buscamos discutir neste artigo são os dilemas e impasses gerados no momento inicial do estabelecimento daqueles e as respectivas respostas desenvolvidas pelas autoridades responsáveis.

\section{Hospedarias de imigrantes: dispositivos de recepção}

O intenso movimento populacional da Europa para as Américas na segunda metade do século XIX, especialmente nas duas últimas décadas, ensejou do lado de cá a preocupação com a recepção desses imigrantes. Em 1881, o ministro da Agricultura do Império do Brasil, José Saraiva, se apressou em propor a construção de um edifício para tratar convenientemente desse enorme afluxo de pessoas. Era preciso registrar, identificar as "aptidões", acomodar provisoriamente e alocar essas pessoas em locais de trabalho.

Durante o século XIX, "locais de recepção" foram criados por particulares, por vezes com subsídio público, para "agasalhar" os imigrantes. Pequenas hospedarias, privadas ou públicas, enfrentaram os dilemas para estabelecer um conjunto de procedimentos para abrigar ${ }^{2}$ os recémchegados: os cuidados higiênicos, a constituição de um corpo de funcionários e de serviços especializados, a identificação de um local pertinente a estas funções, a atenção com as bagagens, a administração de transportes para o destino, entre outras demandas que afloraram no curso do processo. 
(UDAETA, 2013; CHRYSOSTOMO; VIDAL, 2014). Na década de 1880, a Hospedaria da Ilha das Flores, no Rio de Janeiro, e a Hospedaria do Brás, em São Paulo, representaram o amadurecimento desse processo, em um momento em que se intensificou, de modo inédito, o volume de imigrantes que ingressaram no País.

Por todo o continente americano foram estabelecidos dispositivos para a recepção dos estrangeiros que aportavam neste lado do Oceano Atlântico em busca de trabalho. As hospedarias constituíram apenas um dos fios da grande teia que enredava os movimentos migratórios e os vários procedimentos e serviços, criados para levar milhões de europeus de sua origem ao destino americano. Havia uma extensa cadeia de elos que se iniciava na saída dos europeus de suas aldeias e cidades natais - muitas vezes, aliciados por agentes locais e internacionais e estimulados pela propaganda do Novo Mundo - até a chegada a um local de trabalho nas Américas, passando pelos trâmites oficiais da emigração nos portos e pelos dissabores do transporte nos vapores transatlânticos. ${ }^{3}$

De forma similar ao que ocorreu no Brasil, os países que receberam grandes levas de europeus, a partir de meados do século XIX - especialmente Estados Unidos, Canadá e Argentina -, organizaram os seus dispositivos de recepção. Foram estabelecidas grandes hospedarias, todas no litoral, em locais estratégicos para o aportamento dos vapores europeus e por onde ingressou a maior parte dos imigrantes.

A mais conhecida internacionalmente é Ellis Island, localizada em Nova Iorque, EUA. Funcionou entre 1892 e 1954. Estima-se que 40\% dos cidadãos norte-americanos atuais tenham antecedentes que passaram por esta instituição. (MORENO, 2004; CANNATO, 2009). Ellis Island foi precedida por Castle Garden (1855-1890), administrada pelo estado de Nova Iorque, que recebeu cerca de 8 milhões de imigrantes.

O prédio de Ellis Island, construído em madeira especialmente para os encargos de recepção dos imigrantes, foi vítima de incêndio em 1897. Nova edificação "à prova de fogo" foi construída, e a hospedaria reabriu as portas em 17/12/1900, dia em que recebeu 2.251 imigrantes. Era um complexo onde funcionava, entre outros, um setor de desinfecção de pessoas e roupas, sala de registro, dormitórios masculinos e femininos, restaurante, hospital, depósito de bagagens, escritório de telégrafo e caminho para a ferrovia. A grande maioria, cerca de $80 \%$, permanecia na Ilha por aproximadamente 5 horas; poucos ficavam por dias. Ellis Island não foi exatamente uma hospedaria, mas um lugar de registro e controle da entrada de imigrantes. 


\section{Hospedarias de Imigrantes nas Américas: a criação da hospedaria da Ilha das Flores}

Entre 1900 e 1914, cerca de 5000 a 10000 pessoas passavam diariamente por ali; em 1907, ano de pico, entraram 1.250.000 pessoas; entre 1892 e 1924, passaram cerca de 12 milhões pela Ilha. Os números correspondem à massiva leva migratória que se encaminhou para os Estados Unidos. ${ }^{4}$

Com a entrada dos EUA na Primeira Guerra Mundial, em 1917, Ellis Island se transformou em centro de detenção para os inimigos estrangeiros. O mesmo ocorreu durante a Segunda Guerra Mundial. O confinamento na Ilha também atingiu, logo após o fim da Primeira Guerra, com o chamado "perigo vermelho", vários suspeitos "radicais".

Halifax, capital da Província de Nova Escócia, no litoral Atlântico, foi, ao menos desde o século XIX, o principal ponto de chegada de imigrantes no Canadá. Por ali, no Píer 2, foram estabelecidos os primeiros escritórios para assistência e controle dos recém-chegados em fins daquele século. Após um incêndio em 1895, o Píer foi reconstruído e reaberto em 1915, para sofrer uma explosão em 1917. (DODGE, [s.d.]; LEBLANC, 1988; GRANFIELD, 2000). Uma nova estrutura foi construída e, a partir de 1924, imigrantes começam a ser recebidos no complexo do Píer 21. Conectado à estação ferroviária, manteve escritórios de imigração e alfândega, serviços médicos, cozinha, hospital, berçário, dormitórios e um centro de detenção. Durante o período de funcionamento, por ali passou cerca de um milhão de imigrantes.

$\mathrm{Na}$ Argentina, desde princípio do século XIX, o governo alugava espaços para alojar imigrantes. Entre 1882 e 1911, funcionou a primeira hospedaria oficial, o Hotel de los Inmigrantes de La Rotonda. Por ali entraram cerca de 1.400 .000 imigrantes, o que equivalia a $50 \%$ do total dos que ingressaram na Argentina nesse período. ${ }^{5}$ Em 1911, foi inaugurado o que seria a hospedaria definitiva em Buenos Aires, ao lado do porto. Era um grande prédio de quatro pisos, com capacidade de alojamento para 4000 pessoas. O refeitório estava preparado para atender quase 1000 pessoas por vez. Havia ainda depósitos para bagagens, hospital, padaria, carpintaria, oficina de correios e telégrafos, assim como escritórios para registro e controle. Os imigrantes ficavam ali, em média, cinco dias, até conseguir trabalho. Entre 1911 e 1920, a hospedaria alojou cerca de 500 mil pessoas.

No Brasil, durante a Grande Imigração, foram criadas inúmeras hospedarias, ao norte e ao sul, como, por exemplo, em Belém (PA), Florianópolis (SC), Porto Alegre (RS) e Vitória (ES), todas no litoral. Esta última, instalada em 1889, funcionou durante cerca de 30 anos e, na primeira década, chegou a receber 20 mil imigrantes. $\mathrm{O}$ mesmo ocorreu nos cinco primeiros anos de funcionamento da Hospedaria de Cristal, em Porto Alegre, criada em 1890. (SILVA, 2014).

Nem todas as hospedarias, entretanto, se localizaram no litoral. Juiz de Fora (MG) sediou a Hospedaria Horta Barbosa, criada em 1888 e desativada na primeira década do século XX. Localizada 
estrategicamente, com fácil acesso rodoviário e ferroviário, funcionava como local de acolhida aos imigrantes que chegavam de diversos portos, principalmente do Rio de Janeiro, com destino a Minas Gerais.

A maior delas, em tamanho e número de imigrantes recepcionados, foi a Hospedaria do Brás, em São Paulo. Recepcionou 3.500.000 imigrantes entre 1888 e 1978. A edificação tinha dois andares: no andar térreo ficavam os escritórios, a casa de câmbio, a sala médica, as cozinhas, os refeitórios e as salas de armazenagem. No andar superior localizavam-se os dormitórios, que muitas vezes tinham apenas esteiras para as pessoas dormirem. (PAIVA; MOURA, 2008).

Construída para abrigar cerca de 4 mil pessoas, a Hospedaria de Imigrantes encarregava-se de receber e direcionar os trabalhadores estrangeiros para todo o estado de São Paulo. Ficava ao lado de um desvio da ferrovia que ligava Santos a Jundiaí e que trazia os imigrantes para a capital e levava o café diretamente para o Porto de Santos.

Anteriormente, em 1878, o governo provincial de São Paulo instalara no bairro de Santana sua primeira hospedaria oficial, que foi desativada em 1880. Foi substituída pela Hospedaria do Bom Retiro, que abriu as portas em 1882, com capacidade para 500 pessoas. Pequena para o fluxo que se intensificava, a Bom Retiro levou seu tiro de misericórdia em 1887, quando ali surgiu um surto de varíola e difteria. A partir de então, passa a funcionar a Hospedaria de Imigrantes do Brás, oficialmente inaugurada em 1888.

Recepção, triagem e encaminhamento era o tripé que determinava a estadia do imigrante na hospedaria. Os serviços de alimentação e alojamento eram intercalados com os de controle médico sanitário, registro e direcionamento ao trabalho. Os serviços de higiene incluíam banho, desinfecção e troca de roupas e inspeção médica. O tempo médio de permanência dos imigrantes era de uma semana.

\section{Uma política brasileira para a imigração}

A experiência da imigração europeia para o Brasil data do período joanino e fixa raízes que perduram por todo o período imperial. Logo após o estabelecimento da Corte portuguesa em território americano, o monarca, visando à formação de colônias para ocupação do território brasileiro, firmou contratos para atração de europeus. (NICOULIN, 1995). Subsidiava-se a viagem e o estabelecimento com a concessão de terras, ferramentas e sementes - de colonos em áreas interioranas. Essa concepção colonizadora norteou as diretrizes da administração imperial até a década de 1870. (CARNEIRO, 1950). 


\section{Hospedarias de Imigrantes nas Américas: a criação da hospedaria da Ilha das Flores}

A partir de meados do século XIX novas perspectivas são associadas à imigração. A extinção do tráfico de escravos (1850) e a promulgação da Lei do Ventre Livre (1871) colocavam em pauta o fim da escravidão e a necessidade de braços para a grande lavoura. O senador Vergueiro propôs, como solução para o problema, as colônias de parceria com imigrantes europeus. (HOLANDA, 2004). Os precários resultados desta experiência não animaram os proprietários. Debates acalorados foram travados sobre a questão, e chegou-se a especular a atração de asiáticos. Em 1878, o Presidente do Conselho de Ministros e Ministro dos Negócios da Agricultura, Comércio e Obras Públicas, o Visconde de Sinimbu, convocou o Congresso Agrícola, no Rio de Janeiro. Foram arregimentados os proprietários das províncias do Rio de Janeiro, São Paulo, Minas Gerais e Espírito Santo e do Município Neutro para debater as necessidades da grande lavoura em termos de mão de obra, crédito e tecnologia. "O congresso permitiu que, pela primeira vez na história do Brasil independente, os proprietários pudessem falar aberta e diretamente ao governo, em vez de fazê-lo por intermédio da representação parlamentar ou das poucas associações de classe”. (CARVALHO, 1988, p. v). Não houve consenso sobre uma série de questões, mas o problema da mão de obra foi identificado como o principal do setor agrícola daquele momento. Para muitos, a imigração colocava-se como uma das possibilidades para solucioná-lo.

O governo imperial passou a dividir com as administrações provinciais e com a iniciativa privada as ações de atração de imigrantes para o País. A política colonizadora foi, em grande medida, mantida pela administração imperial, enquanto as províncias e os particulares passaram a incentivar a vinda de imigrantes para garantir braços para a grande lavoura. Neste último caso destacaram-se os presidentes da província e os cafeicultores de São Paulo que criaram agremiações promotoras da imigração. (BEIGUELMAN, 1985; GONÇALVES, 2012; KLUG, 2009, p. 199-231; OLIVEIRA, 2001; PETRÔNIO, 2004). Os serviços de recepção e encaminhamento dos imigrantes a seus destinos incorporavam-se a esses debates.

Nesse cenário, em 1876 o Ministério da Agricultura promoveu a reestruturação dos departamentos dedicados à imigração, colonização e gestão das terras públicas. A Agência Oficial de Colonização e a Comissão do Registro Geral e Estatística das Terras Públicas e Possuídas foram extintas, e suas atribuições, transferidas para a Inspetoria Geral de Terras e Colonização. Cabia-lhe “desde o transporte marítimo e por terra até a alimentação, socorros médicos, e o mais que se fazia mister ao recebimento e agasalho de milhares de imigrantes, tudo foi prevenido com boa ordem, economia e a contento dos internados". (ALMEIDA, 1877, p. 404). 
Uma das principais preocupações da Inspetoria, imediatamente após sua criação, em 1876, era a proteção dos imigrantes em relação às doenças que assolavam a Corte Imperial. Na cidade do Rio de Janeiro ao longo do século XIX, especialmente na sua segunda metade, irromperam muitas epidemias. A primeira grande epidemia de febre amarela ocorreu entre 1849 e 1850, atingindo mais da metade da população e deixando um saldo de mais de quatro mil mortos. Tal era a gravidade da situação que o governo nomeou, nesse mesmo ano, uma Junta de Higiene para acompanhar os trabalhos de controle de epidemias e dotou-o de um serviço de estatística, ao que parece, o primeiro da América do Sul. Durante toda a segunda metade do século XIX, a febre amarela assolou a cidade, deixando muitos mortos. Nos anos 1870, os dois surtos mais graves ocorreram em 1873 e 1878. Cólera-morbus, varíola, tuberculose, doenças intestinais e malária também foram flagelos crônicos no Rio de Janeiro. (CHALLOUB, 1996; BENCHIMOL, 2001). Esse quadro epidêmico promoveu campanhas anti-imigratórias para o Brasil na Europa. A Prússia, em 03/11/1859, proibiu seus cidadãos de partir para São Paulo. Em 1871, a proibição foi estendida para todo o país. Medida semelhante foi adotada pela Inglaterra e França, respectivamente em 1875 e 1876. (ZAIDMAN, 1983, p. 38).

$\mathrm{O}$ isolamento dos imigrantes em sanatórios, "pontos bem reputados por suas condições de salubridade" (ALMEIDA, 1877, p. 404), foi a solução encontrada à época para proteger os recémingressados no País, assim como para tentar mudar a imagem externa que se consolidava. Inicialmente tais espaços eram alugados a particulares, como, por exemplo, a hospedaria do Morro da Saúde. Essas instituições foram concebidas para isolar os imigrantes recém-chegados da cidade febril e, consequentemente, impedir sua morte. A preocupação das autoridades era não deixar que a força de trabalho europeia, sadia e vigorosa, fosse penalizada e enfraquecida pela situação insalubre da cidade.

A Hospedaria de Imigrantes do Morro da Saúde foi criada em 26/03/1867, por consequência do arrendamento dos prédios de José Rodrigues Ferreira, feito pelo Ministério da Agricultura, e tinha capacidade para 400 pessoas. Com sua criação, a administração imperial substituía as hospedarias privadas da Praia Formosa e a da Rua da Imperatriz, de menor capacidade. Iniciou suas atividades em 14/04/1867 recebendo 33 norte-americanos. (OLIVEIRA, 2008). Era tida como superior ao Castle Garden de Nova York:

O Ministério da Agricultura tem hoje pronto para a recepção de imigrantes um belo estabelecimento que corresponde em sua destinação à casa de recepção de Castle Garden em Nova York, mas, que lhe é muito superior no seu estilo geral e nas comodidades preparadas para os imigrantes. ${ }^{6}$ 
Em 1876 esta hospedaria sofreu com a infestação pela febre amarela, obrigando-se a administração a fechá-la e a alugar alojamentos em Mendes, Barra do Pirahy, e na Colônia de Porto Real, no interior da província do Rio de Janeiro. (CINTRA, 1877, p. 7-9). Passado o surto epidêmico, a casa foi reaberta no ano seguinte. Em 1881, a Hospedaria do Morro da Saúde foi novamente fechada, e os imigrantes foram alojados em um navio do Ministério da Guerra, fundeado na Baía de Guanabara, ou transportados diretamente para São Paulo. (CARVALHO, 1882). Essa precarização levou os gestores da Inspetoria e do Ministério à proposição da criação de uma estalagem em local adequado: a Ilha das Flores.

A preocupação com a salubridade dos espaços de recepção e abrigo dos imigrantes chegados recentemente foi uma constante na administração pública. Em 1886, por exemplo, um navio que aportara no Rio de Janeiro, após inspeção médica, não foi autorizado a desembarcar os tripulantes, pois foram considerados infectados por moléstia contagiosa, sendo direcionados para a Ilha Grande. ${ }^{7}$ (SILVA, 1887, p. 29-30).

\section{A Ilha das Flores: um local adequado}

O aumento do ingresso de imigrantes no País e a percepção da inadequação da hospedaria do Morro da Saúde ensejaram o projeto de definição de um espaço específico para atendimento dos recém-ingressados, assim como a construção de um prédio próprio e adequado para tal fim. Em 1881, o ministro, acatando sugestão do Inspetor de Terras e Colonização, estabelece quatro providências para preparar a administração pública para a ampliação do número de imigrantes no País:

$1^{\circ}$ Construção de um edifício adequado à recepção de imigrantes, em condições de comportar o movimento anual de 50.000 indivíduos; e organização de um serviço de informações, locação e venda de terras que habilite o colono recém-chegado a colocarse convenientemente segundo a sua aptidão, e no menor prazo;

$2^{\circ}$ Hospedagem até 8 dias;

$3^{\circ}$ Transporte gratuito da Côrte para as províncias e daí para as localidades onde os imigrantes houverem de ser colocados;

$4^{\circ}$ Aquisição de terrenos quando os não houver devolutos à margem de ferrovias, estradas de rodagem e vias navegáveis para fundação de núcleos só provisoriamente e por curto prazo subordinados à inspeção do Estado. (SARAIVA, 1882, p. 208).

Com o objetivo de construir uma hospedaria adequada, a Inspetoria Geral de Terras e Colonização apresentou projeto e orçamento à Inspetoria Geral de Obras Públicas. Quanto ao local, não mencionado, não foi aceito pelo presidente da Junta Central de Higiene Pública, provavelmente por ter sido considerado insalubre. O Inspetor interino sentenciava os benefícios dessa obra: “é 
indubitavelmente esse um grande melhoramento que virá satisfazer, seu o serviço interno compreender todos os ramos que lhe são inerentes, uma de nossas mais palpitantes necessidades da atualidade". (CARVALHO, 1882, p. 6).

Em 16/01/1883 foi lavrada a escritura de compra da Ilha das Flores com a finalidade de ali se construir o prédio da Hospedaria. Esta ilha e outras próximas eram de propriedade do senador José Ignácio Silveira da Motta. (ESCRITURA, 1883). O interesse do governo imperial na Ilha das Flores data de 1876, quando ali foi enviada uma comissão do Imperial Instituto Fluminense de Agricultura, órgão vinculado ao Ministério da Agricultura, para avaliar as experiências de piscicultura em curso. Em seu relatório, a Comissão a descrevera: "o terreno da ilha está, em grande parte, inculto; a porção, porém, aproveitada em jardim, horta, pomares e roças mostra a feracidade natural, pelo desenvolvimento e viço do arvoredo e plantações". (IMPERIAL, 1876, p. 3). Constatava-se a produtividade pelo elevado número de árvores frutíferas - havia 800 videiras carregadas -, leguminosas na horta, e se plantava mandioca para a rodução da fécula. A ilha contava ainda com galinheiros e currais.

Além da casa de morada do senador, que continha um anexo para a recepção de hóspedes, a ilha possuía armazéns destinados à guarda de instrumentos de trabalho, barcos, etc. e residências dos empregados dispersos no local.

Desenvolvia-se ali a criação intensiva de peixes em seis tanques que comportavam até doze mil peças. A referida Comissão, tendo em vista a crescente demanda de alimentos, gerada pelo aumento populacional das duas capitais - a Corte e Niterói, capital da província do Rio de Janeiro -, avaliava como positiva a experiência que ali se desenvolvia e propunha a aquisição da ilha para dinamizar aquela prática e desenvolvê-la em outros centros pesqueiros. O plano, porém, se alterou conforme os rumos assumidos pela política imigrantista.

Logo após a aquisição iniciaram-se as obras de construção do prédio da Hospedaria, que teria capacidade de atendimento de 800 a 1000 imigrantes por vez. Enquanto o prédio não estava concluído, o serviço de acolhimento dos estrangeiros era realizado na hospedaria do Morro da Saúde, uma estalagem particular no Baldeador, Niterói, e utilizavam-se instalações existentes na Ilha do Carvalho. (ÁVILA, [s.d], p. 222).

A escolha deste local se deveu a dois critérios. Em primeiro lugar, por sua salubridade. Sendo uma ilha, não mantinha contato permanente com os centros administrativos da nação - a cidade do Rio de Janeiro e a província fluminense, a cidade de Niterói - nem com suas constantes epidemias. ${ }^{8} \mathrm{O}$ relatório da visita dos representantes ministeriais, em 1876, destacava as potencialidades produtivas e 
sanitárias do lugar. Por outro lado, a ilha situa-se na Baía de Guanabara, no território niteroiense, e poderia ser facilmente acessada por navios de pequeno porte a partir do porto do Rio de Janeiro. Estar próximo à capital fluminense denotava poder contar com o uso dos hospitais locais, São João Batista e Santa Isabel, para o atendimento de casos mais graves. Estar próximo à Corte significava maior atuação da gestão imperial sobre aquela iniciativa que atraía o olhar de outras províncias.

A questão sanitária era uma constante nos relatórios. A preocupação era demonstrar que a hospedaria era um sanatório plenamente capaz de atender às demandas do abrigo dos imigrantes antes de sua transferência para os destinos finais. Registrando o primeiro ano de funcionamento da hospedaria (1883), Affonso Penna, então ministro da Agricultura, afirmava que

o estado sanitário manteve-se inalterado, não tendo falecido senão seis imigrantes, dos quais um por efeito de hemorragia cerebral, dois por efeito de asfixia por submersão, um adulto e duas crianças de meses que desembarcaram para a ilha moribundos por efeito de angina. (PENNA, 1884, p. 216).

O seu sucessor, João Ferreira de Moura, no ano seguinte (1884), afirmava que

acha-se bem organizado ali o serviço sanitário [...] tendo eu mesmo sido testemunha, na visita que ali fiz, das boas condições que o estabelecimento apresenta, para que, com pouco mais, corresponda plenamente ao fim que o Governo teve em vista, quando resolveu fundá-lo. (MOURA, 1885, p. 361).

Ao último ministro da Agricultura do Governo Imperial, Rodrigo Augusto da Silva, o inspetor Geral das Terras e Colonização, Francisco de Barros e Accioli de Vasconcellos, afirmava que

Durante 3 anos e 10 meses de existência tem sido alojados na Ilha das Flores 38.680 imigrantes, dos quais 12.501 no ano findo. Em tão largo período, no decurso do qual mas de uma vez tem grassado com intensidade não só no porto, como na cidade de Niterói e do Rio de Janeiro, moléstias epidêmicas, é agradável registrar, nenhum caso de moléstia se deu que revelasse sintoma epidêmico, e menos, que produzisse a morte no indivíduo acometido. Os falecimentos, que ali se tem dado em número muito limitado, são provenientes de enfermidades contraídas durante a viagem, sendo na maior parte, de crianças. (VASCONCELLOS, 1887, p. 9).

\section{A hospedaria de imigrantes da Ilha das Flores. Estruturação a partir da experiência}

Desde fins da década de 1870, o incentivo à imigração era a tônica dos discursos ministeriais. ${ }^{9}$ Projetavam-se mudanças nas práticas de atração e fixação de imigrantes, tendo-se como parâmetros as experiências norte-americanas e argentinas. Incentivava-se a propaganda que os colonos já residentes 
pudessem fazer junto a suas famílias e amigos; investia-se na mudança da imagem do País no exterior; realizavam-se contratos com particulares ou agremiações para arregimentar imigrantes. Em paralelo, a política de colonização foi revista. Entre outras ações, foram estabelecidas regras para aquisição de lotes e materiais de infraestrutura para a fixação de novos núcleos coloniais, e regularizadas atividades laborais para ocupação dos colonos até que a primeira safra fosse colhida e que estivessem consolidados.

A par disso, não se tinha noção da estrutura que seria necessária para a recepção dos imigrantes. Ao iniciar os trabalhos, a Hospedaria da Ilha das Flores tinha capacidade para receber até 1000 imigrantes por vez e acolheu, em 1883, 7.402. Sete anos depois, em 1890, foram registrados 66.494 recepcionados naquele espaço, conforme tabela abaixo:

Tabela 1 - Ingresso de Imigrantes

\begin{tabular}{|c|c|c|c|}
\hline Ano & $\begin{array}{c}\text { Hospedaria da Ilha } \\
\text { das Flores }\end{array}$ & $\begin{array}{c}\text { Porto do Rio de } \\
\text { Janeiro }\end{array}$ & Brasil \\
\hline 1883 & 7.402 & & 24.827 \\
\hline 1884 & 8.138 & 17.999 & 19.608 \\
\hline 1885 & 10.579 & 22.727 & 29.408 \\
\hline 1886 & 12.501 & 22.236 & 25.741 \\
\hline 1887 & 18.834 & 33.310 & 54.990 \\
\hline 1888 & 33.384 & 55.863 & 65.187 \\
\hline 1889 & 26.848 & & 107.100 \\
\hline 1890 & 66.494 & 85.162 & \\
\hline
\end{tabular}

Fonte: Relatórios Ministeriais. 1884-1890

O crescimento constante gerou a necessidade de ampliar e complexificar a estrutura de abrigo ali em curso. Foi a percepção do fluxo imigratório crescente que obrigou os agentes administrativos a intervirem na Hospedaria, construindo novos espaços e serviços.

Ao iniciar suas atividades, a Hospedaria da Ilha das Flores era constituída de

[...] um galpão construído de tijolo e frontal, medindo $71 \mathrm{~m}$ de comprimento sobre $13 \mathrm{~m}$ de largura, não compreendidas as varandas laterais, e dividido em quatro grandes salões para dormitório, três salas para enfermaria e consultório médico, e outros sete compartimentos para dependências do serviço de hospedagem de imigrantes. O refeitório e cozinha estão provisoriamente instalados em antigos telheiros, achando-se em construção um edifício para deposito de bagagens e viveres, cozinha e copa. Não 
existindo na ilha senão um depósito com a capacidade necessária para conservar 63.000 litros d'água, deu-se começo à construção de outro com capacidade para 40.000 litros. (PENNA, 1884, p. 215-216).

O ministro tinha ciência de que a estrutura criada passaria por alterações futuras em decorrência das necessidades advindas com a ampliação do afluxo de imigrantes ao País. "Outros melhoramentos irão sendo realizados à proposição das necessidades, tendo-se à vista que ao imigrante recém-chegado não faltem condições de conforto". (PENNA, 1884, p. 216). Em sua descrição, elenca quatro temas que envolverão a gestão do Ministério da Agricultura no final do século XIX e em princípios do XX.

O primeiro deles diz respeito aos alojamentos para abrigar os imigrantes. Em 1883, a Hospedaria era composta de um único prédio compartimentado entre os dormitórios, dependências médicas e administrativas. O aumento da capacidade de absorção dos recém-chegados levou à construção, em 1888, de novos alojamentos, estendendo-se sua capacidade total para 2000 pessoas. (VASCONCELLOS, 1889, p. 10).

Entre 1883 e 1891, o número de internos na ilha aumentou exponencialmente. Além dos dormitórios, foram construídas outras dependências necessárias a suas necessidades. A cozinha e o refeitório originais foram alojados em antigos telheiros já construídos no engenho de Silveira da Motta. Em 1888, mais um refeitório foi construído. (VASCONCELLOS, 1889, p. 10). Dois anos depois, 1890, novas cozinhas e refeitórios foram erguidos. (LUCENA, 1891, p. 104). Por demanda dos imigrantes, foi construída uma lavanderia, em 1885. (VASCONCELLOS, 1886, p. 6).

O segundo alvo de preocupações eram os espaços reservados aos doentes. Ao ser construída, a Hospedaria possuía duas enfermarias e um consultório médico no prédio dos alojamentos. Estas dependências deveriam ser usadas apenas para casos de doenças simples. Ao chegar ao Porto do Rio de Janeiro, o navio era inspecionado pelo médico da Hospedaria. Os passageiros com doenças graves eram transferidos para hospitais da Corte ou de Niterói. Os navios que comportavam graves problemas eram isolados na Ilha Grande, no sul fluminense. Para aviamento ágil dos medicamentos necessários aos cuidados dos doentes na Hospedaria, em 1884 foi criada uma botica. (MOURA, 1885, p. 361).

Em 1886 foi construído um prédio específico para enfermaria. Com tal medida cumpriam-se duas prerrogativas das ações governamentais na ilha. O novo prédio isolava os doentes do contato com os imigrantes sadios e, por outro lado, ampliava o espaço destinado aos dormitórios. (VASCONCELLOS, 1887, p. 9). Em 1891 a Hospedaria ganhou novas enfermarias, tendo-se em vista o volume de imigrantes que abrigava. (ABREU, 1892, p. 13).

A despeito das precauções, em 1899 a Hospedaria da Ilha das Flores sofreu um surto de febre amarela, pois, "apesar dos cuidados para impedir o aparecimento de doenças contagiosas estas são História (São Paulo) v.33, n.1, p. 234-253, jan./jun. 2014 ISSN 1980-4369 
difíceis de serem controladas devido a constante relação dos imigrantes com a população da capital". (MAIA, 1900, p. 72-73).

A recepção e o transporte das bagagens dos imigrantes foram o terceiro universo de questões que envolveu a administração ministerial. As bagagens eram verificadas nos navios ou na própria Hospedaria. A recepção delas era um problema. Ao aportar no Rio de Janeiro, os passageiros desembarcavam, e aqueles que não possuíam destino prévio eram encaminhados à Hospedaria da Ilha das Flores. Suas bagagens muitas vezes não eram desembarcadas, e os navios seguiam viagem. Por vezes, os imigrantes eram enviados à hospedaria, e suas bagagens eram remetidas dias depois, quando já tinham partido para seu destino final. Visando à solução e a evitar problemas de envio desses pertences, o ministério passou a cobrar dos capitães dos navios maior agilidade na liberação das bagagens. Não tendo surtido o efeito esperado, passou a designar um funcionário para ir a bordo e as localizar. Por fim, o Ministério passou a se responsabilizar pelos extravios, indenizando as perdas. Em 1888 foi construído o primeiro galpão específico para o armazenamento das bagagens e também foram comprados equipamentos de desinfecção. (VASCONCELLOS, 1889, p. 12-13).

Por fim, a estrutura administrativa e de serviços para o atendimento dos imigrantes foi sendo ampliada conforme o crescimento da demanda.

Ao ser criada, a hospedaria passou a contar com José Xavier da Cunha como seu administrador. O regulamento provisório que organizava o funcionamento da instituição estabelecia seu quadro funcional, que seria composto por 15 trabalhadores fixos: um ajudante da administração, um médico, um farmacêutico, um escrivão, um almoxarife, um fiel, um encarregado de armazém de bagagem, um maquinista, dois auxiliares intérpretes internos, um feitor, um enfermeiro, dois ajudantes de enfermaria (sendo um deles mulher, para a enfermaria feminina). Além destes, o diretor da hospedaria poderia contar ainda com um amanuense para o escritório, guarda para o almoxarifado e para o serviço de bagagens, intérpretes externos, cozinheiros e ajudantes, serventes, vigias de portos, encarregados de refeitório, da iluminação e das latrinas. (REGULAMENTO, [s.d.]). Não sabemos se o estabelecimento pôde contar com todos esses funcionários no início de suas atividades. Certo é que o crescimento do número de internos gerou a ampliação do quadro funcional e promoveu a necessidade de construção de espaços específicos para estes.

Cinco anos depois de inaugurada (1888), foi construído um prédio para a Secretaria da Hospedaria. (VASCONCELLOS, 1889, p 10). Em 1890, ano de auge de recepção de imigrantes, foi necessária a construção de um refeitório e uma cozinha específica para os funcionários. (LUCENA, 1891, p. 104). No ano seguinte, foi construída uma casa para o ajudante do diretor. (ABREU, 1892, p. 
14).

Em conjunto, era necessário a autonomização da hospedaria frente a uma série de questões infraestruturais, como o abastecimento de água. Desde sua criação, a estalagem era abastecida de água potável pelo Arsenal da Marinha do Rio de Janeiro. Originalmente, em 1883, havia dois reservatórios com capacidade total de 103.000 litros de água. (PENNA, 1884, p. 216). Dois anos depois, 1885, foi construído um terceiro reservatório para 70.000 litros. No ano seguinte, foram criados uma cisterna e um sistema de captação de água da chuva. (VASCONCELLOS, 1886, p. 6).

Nesse universo, outra preocupação era o transporte dos imigrantes do Porto do Rio de Janeiro para a Ilha e desta para o destino final. Para fazer o translado entre a Corte e a Ilha, em 1883 o Ministério da Marinha havia disponibilizado uma lancha, e o Ministério da Agricultura autorizou a compra de duas outras embarcações. (PENNA, 1884, p. 217). No ano seguinte, 1884, já se contava com a lancha e 3 batelões. (MOURA, 1885, p. 361). Dois anos depois, 1886, havia 2 lanchas, 2 batelões e se utilizava o serviço de barcos particulares nos períodos de maior afluxo. (VASCONCELLOS, 1887, p. 12-13). Como resultado do ápice de recepção dos anos de 1890 e 1891, o relatório de 1892 registra que a hospedaria contava com oito embarcações: 3 vapores e 5 batelões (Relatório de 1892).

\section{Considerações finais}

A Hospedaria de Imigrantes da Ilha das Flores foi a primeira instituição oficial para recepção de imigrantes estabelecida pelo governo imperial. Sua criação só foi possível após alterações nas políticas públicas de imigração dirigidas pelo Ministério da Agricultura. A criação de uma hospedaria oficial foi projetada em 1876; no entanto, permaneceu letra morta até 1881. Visconde de Sinimbu, Ministro da Agricultura entre 1877 e 1878, argumentando sobre a necessidade de sanar déficits de recursos, levou ao fim o financiamento da imigração e da colonização. Em 1879 o quadro começou a mudar com a retomada da política imigrantista e colonizadora. $\mathrm{O}$ antigo projeto de construção de uma hospedaria governamental retornou à pauta do dia, e foram iniciadas as negociações para a compra da Ilha.

As propostas das autoridades imperiais baseavam-se em um aprendizado acumulado acerca da recepção de imigrantes, ao longo do século XIX, na Corte e na província do Rio de Janeiro, realizado mediante subvenção de hospedarias particulares. Entretanto, conforme argumentamos, isso não foi suficiente para resolver os impasses que apareceram com a chegada massiva de imigrantes. A Hospedaria da Ilha das Flores, tão logo foi aberta, necessitou de inúmeras adaptações e reformas. Em grande parte, as transformações e reestruturações ocorridas devem-se ao ineditismo da experiência de 
receber milhares, dezenas de milhares de imigrantes por ano. A prática cotidiana moldou a estrutura de recepção.

Durante a década de 1880, mais de $70 \%$ dos imigrantes que entraram no Brasil ingressaram pelo porto do Rio de Janeiro. A grande maioria não tinha contatos na terra e passou pelos trâmites de uma hospedaria. Até a instalação da Hospedaria do Brás, em São Paulo, Ilha das Flores fez o papel principal de recepção, acolhimento e triagem para locais de trabalho. Entre 1883 e 1890, recebeu mais de 180 mil imigrantes, dos 450 mil que ingressaram no País. Desta forma tornou-se um dispositivo importante no processo imigratório e alvo de uma contínua ação do Ministério da Agricultura, fosse na reestruturação e complexificação dos serviços ali ofertados, fosse na fiscalização das questões sanitárias, visando a preservar a mão de obra tão necessária para a lavoura.

A recepção aos imigrantes, em fins do século XIX, foi uma experiência comum em toda a América. A hospedaria de imigração foi um dos elos da extensa e complexa cadeia migratória constituída desde a aldeia da terra natal até a chegada ao destino final. Os principais países de imigração - como Estados Unidos, Argentina, Canadá e Brasil - criaram dispositivos similares nos principais portos de chegada, respectivamente, Nova York, Buenos Aires, Halifax, Rio de Janeiro e São Paulo. Nestes termos, foi uma experiência universal. Sabemos pouco ainda sobre as conexões administrativas, políticas e intelectuais entre dirigentes políticos e autoridades administrativas dos diferentes países receptores, que possam evidenciar a circulação de propostas e realizações para a constituição destes dispositivos. Ainda assim, em todas essas instituições houve preocupação com registro pessoal, serviços médicos, alojamento, controle de bagagens, além da existência de meios de transporte contíguos, serviços paradigmáticos constantes de todas elas. Certamente, cada uma das instituições apresentou soluções particulares para cada uma das preocupações listadas acima.

Resta-nos a convicção de que conhecer as hospedarias na sua universalidade e nas suas especificidades pode vir a ser uma forma de compreender como cada uma das sociedades estabeleceu suas relações com o estrangeiro e com o diferente. Nesse sentido, é uma maneira de conhecermos a nós mesmos.

\section{Referências}

ABREU, Candido Ferreira de. Relatório apresentado ao Sr. Ministro da Agricultura, Commercio e Obras Públicas pelo engenheiro Candido Ferreira de Abreu, Inspetor Geral Interino das Terras e Colonização. In: FARIA, Antão Gonçalves de. Relatório apresentado ao Vice-Presidente da 
República dos Estados Unidos do Brasil pelo Ministro D'Estado dos Negócios de Agricultura, Commercio e Obras Públicas, em maio de 1892. Rio de Janeiro: Imprensa Nacional, 1892.

ALMEIDA, Thomaz Jozé Coelho de. Relatório apresentado á Assembléia Geral Legislativa na primeira sessão da décima sexta legislatura pelo Ministro e Secretário de Estado dos Negócios da Agricultura, Commercio e Obras Publicas. Rio de Janeiro: Typographia Perseverança, 1877.

BEIGUELMAN, Paula. A crise do escravismo e a grande imigração. São Paulo: Brasiliense, 1985.

BENCHIMOL, Jaime Larry. Febre amarela: a doença e a vacina, uma história inacabada. 20. ed. Rio de Janeiro: Editora Fiocruz/Bio-Manguinhos, 2001.

CANNATO, Vincent J. American passage: the history of Ellis Island. Harper Perennial, 2009.

CARVAlHO, José Murilo de. Introdução. In: Congresso Agrícola. Edição fac-similar dos Anais do Congresso Agrícola, realizado no Rio de Janeiro, em 1878. Rio de Janeiro: Fundação Casa de Rui Barbosa, 1988.

CARNEIRO, J. Fernando. Imigração e colonização no Brasil. Rio de Janeiro: Universidade do Brasil, 1950.

CARVALHO, Manoel Maria de. Relatório apresentado a S. Ex. Sr. Conselheiro Manoel Alves de Araújo pelo Inspetor Geral interino. Inspetoria Geral das Terras e Colonização. In: ARAÚJO, Manoel Alves de. Relatório apresentado à Assembleia Geral na segunda sessão da decima oitava legislatura pelo Ministro e Secretário de Estado dos Negócios da Agricultura Commercio e Obras Públicas. Rio de Janeiro: Typografia Nacional, 1882.

CHRYSOSTOMO, Maria Isabel de Jesus; VIDAL, Laurent. Do depósito à hospedaria de imigrantes: gênese de um "território da espera" no caminho da emigração para o Brasil. História, Ciências, Saúde - Manguinhos, Rio de Janeiro, v. 21, n.1, fev. 2014.

CHALlOUB, Sidney. Cidade Febril: cortiços e epidemias na Corte imperial. São Paulo: Companhia das Letras, 1996.

CINTRA, J. C. Coelho. Relatório da $2^{\text {a }}$ Secção da Inspetoria Geral de Terras e Colonização. 25/11/1876. In: ALMEIDA, Thomaz Jozé Coelho de. Relatório apresentado á Assembléia Geral Legislativa na primeira sessão da décima sexta legislatura pelo Ministro e Secretário de Estado dos Negócios da Agricultura, Commercio e Obras Publicas. Rio de Janeiro: Typographia Perseverança, 1877.

DODGE, Craig. S.d. Remembering Pier 2: Halifax's Other Immigrant Gateway. Disponível em: http://www.pier21.ca/research/pier21/the-first-seventy-five-years. Acesso em: 15 out. 2012.

ESCRITURA de venda da ilha denominada das Flores, dos Ananazes e da Maxingueira, situadas na Bahia do Rio de Janeiro, que fazem o Conselheiro Senador José Ignácio Silveira da Motta e sua mulher a Fazenda Nacional. 1883. Cópia transcrita pelo Instituto Nacional de Imigração de Colonização (INIC). 04/06/1957. In: Livro do Comando da Tropa de Reforço. Mimeo. s/d. Acervo: Ilha das Flores. 
GRANFIELD, Linda. Pier 21: gateway of hope. Tundra Books, 2000.

GONÇALVES, Paulo César. Mercadores de braços: riqueza e acumulação na organização da emigração europeia para o Novo Mundo. São Paulo: Alameda, 2012.

HOLANDA, Sergio Buarque de. As colônias de parceria. In: História Geral da Civilização Brasileira. O Brasil Monárquico, v. 3. Rio de Janeiro: Bertrand Brasil, 2004.

IMPERIAL Instituto Fluminense de Agricultura. Relatório da Commissão encarregada de examinar o estabelecimento de psicultura da Ilha das Flores. Rio de Janeiro: Typographia Nacional, 1876.

KLUG, João. Imigração no Sul do Brasil. In: GRINBERG, Keila; SALLES, Ricardo (orgs). O Brasil Imperial, v. 3. Rio de Janeiro: Civilização Brasileira, 2009, p. 199-231.

KUSHNIR, Beatriz. A hospedaria Central. A ilha das Flores como ante-sala do paraíso. In: HECKER, Alexandre; MATOS, Maria Izilda; SOUSA, Fernando de (orgs.). Deslocamentos \& histórias. Os portugueses. Bauru: Edusc, 2008, p. 59-73.

LEBLANC, J. P.; MITIC, Trudy D. Pier 21: the gateway that changed Canada. Hantsport, Nova Scotia: Lancelot Press, 1988.

LUCENA, Barão de. Relatório apresentado ao Presidente da República dos Estados Unidos do Brasil pelo Ministro D'Estado dos Negócios de Agricultura, Commercio e Obras Públicas, em junho de 1891. Rio de Janeiro: Imprensa Nacional, 1891.

MAIA, Alfredo Eugênio de Almeida. Relatório apresentado ao Presidente da República dos Estados Unidos do Brasil pelo Ministro de Estado dos Negócios da Indústria, Viação e Obras

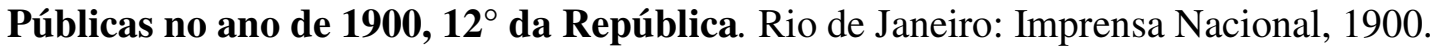

MORENO, Barry. Encyclopedia of Ellis Island. Greenwood Press, 2004.

MOURA, João Ferreira de. Relatório apresentado à Assembleia Geral na primeira sessão da décima nona legislatura pelo Ministro e Secretário de Estado dos Negócios da Agricultura, Commercio e Obras Públicas. Rio de Janeiro: Typografia Nacional, 1885.

NICOULIN, Martin. A gênese de Nova Friburgo. Rio de Janeiro: Biblioteca Nacional, 1995.

OLIVEIRA, Betty Antunes de. Alguns dados históricos da vinda de norte-americanos ao Brasil no século XIX. [S. 1.]: Mimeo, 2008. Disponível em http://www.pibrj.org.br/historia/. Acesso em: 15 out. 2012.

OLIVEIRA, Lucia Lippi. O Brasil dos imigrantes. São Paulo: Jorge Zahar Ed, 2001.

PAIVA, Odair da Cruz; MOURA, Soraya. Hospedaria de Imigrantes de São Paulo. São Paulo: Paz e Terra, 2008.

PENNA, Affonso Augusto Moreira. Relatório apresentado à Assembleia Geral na quarta sessão da 
décima oitava legislatura pelo Ministro e Secretário de Estado dos Negócios da Agricultura, Commercio e Obras Públicas. Rio de Janeiro: Typografia Nacional, 1884.

REBELO, Fernanda. A travessia: imigração, saúde e profilaxia internacional (1890-1926). 2010. Tese (Doutorado) - COC/Fiocruz, 2010.

REGULAMENTO provisório para a hospedaria de imigrantes da Ilha das Flores. Arquivo Público do Estado do Rio de Janeiro. Fundo PP. Notação: Pasta 479. Caixa 181. Maço 03. [s. d.].

PETRÔNIO, Teresa Schorer. Imigração assalariada. In: HOLANDA, Sergio Buarque de (Dir.). História Geral da Civilização Brasileira. O Brasil Monárquico, v. 3. Rio de Janeiro: Bertrand Brasil, 2004.

SARAIVA, José Antônio. Relatório apresentado à Assembleia Geral na primeira sessão da décima oitava legislatura pelo Ministro e Secretário de Estado interino dos Negócios da Agricultura, Commercio e Obras Públicas. Rio de Janeiro: Typografia Nacional, 1882.

SILVA, Gabriela Ucovski da. História e aspectos do cotidiano da Hospedaria do Cristal, Porto Alegre (1890-1898). 2014. Dissertação (Mestrado) - FFCH/PUC, Rio Grande do Sul, 2014.

SILVA, Rodrigo Augusto da. Relatório apresentado à Assembléia Geral na segunda sessão da vigésima legislatura pelo Ministro e Secretário de Estado dos Negócios da Agricultura, Commercio e Obras Públicas. Rio de Janeiro: Imprensa Nacional, 1887.

SOARES, Emmanuel de Macedo. Figura e fatos da medicina em Niterói. Rio de Janeiro: Imprinta, 1994.

UDAETA, Rosa Guadalupe Soares. Nem Brás, nem Flores: hospedaria de imigrantes na cidade de São Paulo (1875-1886). 2013. Dissertação (Mestrado) - FFLCH/USP, São Paulo, 2013.

VASCONCELLOS, Francisco de Barros e Accioli de. Relatório da Inspetoria Geral das Terras e Colonização apresentado a S. Ex. o Sr. Conselheiro Antônio da Silva Prado, Ministro e Secretário de Estado dos Negócios da Agricultura, Commercio e Obras Públicas. Anexo. In: PRADO, Antônio da Silva. Relatório apresentado à Assembléia Geral na primeira sessão da vigésima legislatura pelo Ministro e Secretário de Estado dos Negócios da Agricultura, Commercio e Obras Públicas. Rio de Janeiro: Imprensa Nacional, 1886.

VASCONCELLOS, Francisco de Barros e Accioli de. Relatório da Inspetoria Geral das Terras e Colonização apresentado a S. Ex. o Sr. Conselheiro Antônio da Silva Prado, Ministro e Secretário de Estado dos Negócios da Agricultura, Commercio e Obras Públicas. Anexo. In: SILVA, Rodrigo Augusto da. Relatório apresentado à Assembléia Geral na segunda sessão da vigésima legislatura pelo Ministro e Secretário de Estado dos Negócios da Agricultura, Commercio e Obras Públicas. Rio de Janeiro: Imprensa Nacional, 1887.

VASCONCELLOS, Francisco de Barros e Accioli de. Relatório da Inspetoria Geral das Terras e Colonização apresentado a S. Ex. o Sr. Conselheiro Rodrigo Augusto da Silva, Ministro e Secretário de Estado dos Negócios da Agricultura, Commercio e Obras Públicas. Anexo. In: SILVA, Rodrigo Augusto da. Relatório apresentado à Assembléia Geral na quarta sessão da vigésima legislatura 
pelo Ministro e Secretário de Estado dos Negócios da Agricultura, Commercio e Obras Públicas. Rio de Janeiro: Imprensa Nacional, 1889.

WERHS, Carlos. Niterói. Cidade Sorriso. A história de um lugar. Rio de Janeiro: Soc. Gráfica Vida Doméstica, 1984.

ZAIDMAN, Daiana. A imigração ao Brasil no Império. O caso particular da Hospedaria da Ilha das Flores. 1983. Dissertação (Mestrado em História), Niterói, 1983.

\begin{abstract}
Notas
${ }^{1} \mathrm{O}$ desaparecimento da documentação administrativa da hospedaria poderia, em parte, ser considerado um dos motivos para tal situação. Restaram basicamente os Livros de Registro de Entrada e Saída da Hospedaria, de 1883 e 1932 , que se encontram hoje no Arquivo Nacional, digitalizados em formato facsímile. A dissertação de mestrado de Daiana Zaidman (1983) é um dos poucos trabalhos que se debruçaram sobre a experiência da Hospedaria de Imigrantes da Ilha das Flores. Zaidman, de forma pioneira, buscou analisar os livros de registro de imigrantes da Hospedaria, detendo-se especialmente nos anos iniciais. Realizado há mais de 30 anos, anterior ao processo de digitalização da documentação, a autora incorreu em equívoco ao tomar os livros do Porto do Rio de Janeiro pelos da Hospedaria, invalidando-se as suas conclusões. Daí, ser usual encontrarmos na bibliografia referências à criação da Hospedaria em 1879, conforme afirma a autora. Mais recentemente, Beatriz Kushnir (2008) publicou alguns artigos sobre a temática. O foco de seu trabalho remete à função de quarentena da Hospedaria, como espaço de isolamento contra doenças que os imigrantes trouxessem dos portos de saída. Ao lidar com uma documentação pouco explorada até então, os relatórios do Ministério da Agricultura nos períodos imperial e republicano, observamos que tal hipótese não se confirma para as últimas décadas do século XIX. Sem menosprezar a enorme importância da questão sanitária, como desenvolvemos mais adiante, podemos concluir que a quarentena era realizada em outros espaços.

${ }^{2}$ Termos como abrigar, acolher, depositar, agasalhar eram comuns nos documentos brasileiros do século XIX.

3 A trajetória dos e/imigrantes foram as mais variadas. Por exemplo, muitos chegaram ao Brasil e se estabeleceram na Argentina, passando pelo Uruguai; outros foram contratados já na Europa para trabalhar em fazendas no Brasil. A literatura sobre imigração remete aos mais diversos e inusitados caminhos trilhados pelos emigrantes europeus. Para uma boa descrição da extensa cadeia de agentes da emigração, companhias de navegação, serviços consulares e tantos intermediários que compuseram a extensa cadeia migratória, ver GONÇALVES, 2012.

${ }^{4}$ Não é demais lembrar que a população norte americana cresceu vinte vezes entre 1800 e 1914 , de 5 milhões para cerca de 100 milhões.

${ }^{5}$ Disponível em: http://www.migraventura.net/sites/default/files/Hotel.pdf; http://www.migraciones.gov.ar/pdf_varios/museo/hoteldelinmigrantes.pdf

${ }^{6}$ Este texto foi publicado originalmente no Anglo-Brazilian Times, de 23/04/1867. Foi reproduzido no Diário Oficial do Império, em 02/05/1867 apud OLIVEIRA, 2008, p. 2.

${ }^{7}$ Para a década de 1890, ver REBELO, 2010, p. 33-95.

${ }^{8}$ Niterói foi grassada pela febre amarela em 1849, 1851,1876, 1885, 1886, 1888, 1889; pela varíola em 1849, 1876, 1885, 1886, 1888, 1888,1893; e pelo cólera em 1853, 1867. (WERHS, 1984; SOARES, 1994).

9 Durante a gestão do Visconde de Sinimbú (1877-1878) à frente do Ministério da Agricultura, houve um progressivo esvaziamento da política imigrantista com o corte de verbas, a conclusão de contratos de agenciamento de imigrantes e a autonomização de núcleos coloniais. Seus sucessores, por outro lado, retomaram o incentivo à imigração e direcionaram as ações do Império para a formação de núcleos coloniais.
\end{abstract}

Luís Reznik é doutor em Ciência Política e trabalha no Departamento de Ciências Humanas e no Programa de Pós Graduação em História Social, da Faculdade de Formação de Professores da Universidade do Estado do Rio de Janeiro, e no Departamento de História e Programa de Pós Graduação em História Social da Cultura da Pontifícia Universidade Católica do Rio de Janeiro. 
Rui Aniceto Nascimento Fernandes é Professor Doutor do Departamento de História do Instituto de Filosofia e Ciências Humanas da Universidade do Estado do Rio de Janeiro .

Recebido em 01/03/2014

Aprovado em 26/04/2014 